\title{
Cumulative evidence for association of rhinitis and depression
}

\author{
Jing Wang ${ }^{1 \dagger}$, Dongqiong $\mathrm{XiaO}^{2 \dagger}$, Huayou Chen ${ }^{3}$ and Juan $\mathrm{Hu}^{2^{*}}$ (⿺辶)
}

\begin{abstract}
Background: Several primary studies evaluated the association between rhinitis and the incidence of depression and yielded inconsistent results. We conducted a meta-analysis of studies evaluating the association between rhinitis and depression.

Methods: We searched the EMBASE, PubMed and Cochrane Library databases for studies published in English before April 1, 2019. The studies were included if they reported any type of rhinitis in relation to depression. Two authors independently extracted the data. The odds ratios (ORs) were pooled using a random-effects model. Stratified analyses were conducted to evaluate the association.

Results: Among the 3472 initially identified studies, we included 14 studies involving a total of $19.36 \pm 1.1$ million participants according to predefined inclusion criteria. The associations between rhinitis (R), allergic rhinitis (AR), and nonallergic rhinitis (NAR) and depression were significant with ORs of $1.86(95 \% \mathrm{Cl} 1.32$ to $2.62, p<0.05), 1.54(95 \% \mathrm{Cl}$ 1.24 to $1.90, p<0.05)$, and 2.15 ( $95 \% \mathrm{Cl} 1.49$ to $3.09, p<0.05)$, respectively. The results were consistent and statistically significant in all subgroup analyses.
\end{abstract}

Conclusions: Rhinitis was associated with an increased risk of depression. Further prospective studies involving large sample sizes are required to confirm the results by considering more confounders and clarify the mechanisms.

Keywords: Rhinitis, Depression, Allergic rhinitis, Asthma

\section{Background}

Rhinitis, including allergic rhinitis (AR) and nonallergic rhinitis (NAR), is highly prevalent globally [1-3]. The prevalence of AR ranges from 10 to $40 \%$ worldwide [4-6], and approximately 60 million people are affected by AR and 20 million people are affected by NAR in the United States [7-9]. The magnitude of this public health challenge is increasing, and estimates suggest that at least 1 in 4 people may suffer from rhinitis. The treatments for different forms of rhinitis may differ according to the

\footnotetext{
*Correspondence: hujuan5@163.com

${ }^{\dagger}$ Jing Wang and Dongqiong Xiao contributed equally to this study

${ }^{2}$ Department of Emergency, Key Laboratory of Birth Defects and Related Diseases of Women and Children (Sichuan University), West China

Second University Hospital, Sichuan University, Ministry of Education, Chengdu 610041, China

Full list of author information is available at the end of the article
}

pathogenesis. The severity and persistence of rhinitis may impact the quality of life and, thus, result in many cognitive and emotional adverse events, anxiety and depression [1]. In theory, effective treatments for rhinitis may reduce the risk of developing emotional adverse events.

The prevalence of depression is also increasing, and access to effective treatments remains limited [10], representing a concerning trend given that depression imposes a significant public health burden and large demand on health care systems [11]. Depression treatments are categorized into the following methods: psychotherapy with or without antidepressants and antidepressants only [12].

Several primary studies $[1,3,5-7,13-18]$ evaluated the association between rhinitis and the incidence of depression and yielded inconsistent results. $\mathrm{Lu}$ original author(s) and the source, provide a link to the Creative Commons licence, and indicate if changes were made. The images or other third party material in this article are included in the article's Creative Commons licence, unless indicated otherwise in a credit line to the material. If material is not included in the article's Creative Commons licence and your intended use is not permitted by statutory regulation or exceeds the permitted use, you will need to obtain permission directly from the copyright holder. To view a copy of this licence, visit http://creativecommons.org/licenses/by/4.0/. The Creative Commons Public Domain Dedication waiver (http://creativeco mmons.org/publicdomain/zero/1.0/) applies to the data made available in this article, unless otherwise stated in a credit line to the data. 
et al. [19] reviewed allergic disorders and the risk of depression and allergic disorders, including AR. Additionally, Sansone et al. [20] published a systematic review investigating the relationships between AR and mood syndromes, and 10 of 12 studies showed a positive relationship. Although previous systematic reviews/meta-analyses studied the association between $\mathrm{AR}$ and depression, this manuscript is original because this meta-analysis investigates the association between NAR and depression. Therefore, we conducted a metaanalysis to evaluate the association among rhinitis, AR, NAR and depression.

\section{Methods}

\section{Retrieval of studies}

The reporting of this meta-analysis of observational studies is consistent with the Meta-Analysis of Observational Studies in Epidemiology (MOOSE) guidelines (Additional file 1). The PubMed, EMBASE, and Cochrane Library databases were searched through April 1, 2019. The search consisted of the following two terms: rhinitis and depression. We used the following key words to search for the first term: "rhinitis" OR "rhinit"" OR "NARES" OR "NAR" OR "LAR" OR "NANIPER". We used the following key words to search for the second term: "depression" OR "depressive disorder" OR "depressive disorder, major" OR "dysthymic disorder" OR "depress"” OR "melancholia". In addition, we used "AND" to connect the two terms (for the search strategy, see https://doi.org/ $10.17632 / \mathrm{ccvm} 3 \mathrm{cvbtm} .2)$. The retrieved studies were first screened by reading the titles and abstracts. Two authors (Jing Wang and Dongqiong Xiao) subsequently read the full texts of the remaining publications independently. A third author (Huayou Chen) resolved any disagreements (Additional file 3).

\section{Definitions}

$A R$ is an IgE-mediated inflammatory disease of the nasal mucosa characterized by the presence of one or more nasal symptoms, including itching, sneezing, nasal discharge and nasal blockage [21, 22]. NAR is not IgEmediated rhinitis and consists of at least the following 2 subtypes: a non-eosinophilic subtype and an eosinophilic subtype [23]. Rhinitis is a general term referring to various nose AR/NAR inflammation and infections (viral sinusitis). Depression is based on a highly variable set of symptoms rather than objective diagnostic tests. A diagnosis of major depression was made when a certain number of symptoms listed in the Diagnostic and Statistical Manual (DSM-5) were reported for longer than 2 weeks [24].

\section{Study selection}

The inclusion criteria were as follows: (1) studies involving participants investigated for any of the following outcomes: the incidence, prevalence, risk or odds ratio (OR) of depression among rhinitis, AR, NAR and control participants; (2) studies evaluating the association between rhinitis and depression and reporting the unadjusted and/or adjusted ORs and their corresponding 95\% confidence intervals (CIs), unadjusted and/or adjusted OR estimates and 95\% CIs, or the number of exposed and unexposed participants; and (3) studies published in English with a case-control, cohort, or cross-sectional design.

The exclusion criteria were as follows: (1) studies reporting the results of only animal experiments; (2) unrelated studies or studies in which the data overlapped with those of another study; or (3) reviews, case reports, meta-analyses and letters.

\section{Data extraction}

The data were independently extracted from the studies by two reviewers (Jing Wang and Dongqiong Xiao) and aggregated using a standardized form; the collected data included the study author, publication year, study design, study location, sample size, age, ascertainment of rhinitis, type of rhinitis, ascertainment of depression, depression diagnostic criteria, primary outcomes, confounding factors, data source, and Newcastle-Ottawa Scale (NOS) score.

\section{Quality evaluation}

The methodological quality of all included studies (Additional file 2: Table S1) was examined using the NOS [25] by two reviewers (Jing Wang and Dongqiong Xiao) independently, and a third author resolved any disagreements. The reviewers assessed the quality scores (varying from 0 to 9 ) in the following three domains: selection of the study population, comparability, and evaluation of exposure and outcomes.

\section{Statistical analysis}

The ORs and 95\% CIs were used as measures of the association between rhinitis and depression across the studies. In the case of original studies comparing the number of participants who developed depression following exposure to rhinitis compared with control groups, we calculated the ORs and 95\% CIs of each study. All data from the included studies were converted into $\log (\mathrm{ORs})$ and standard errors (SEs) [26]. We pooled the $\log (\mathrm{ORs})$ and SEs of each study separately using the DerSimonian-Laird formula (random effects model) 
[27]. The statistical heterogeneity [28] among the studies was assessed using the $I^{2}$ statistic [29]. Values of $I^{2}>50 \%$ and $p<0.1$ indicated high heterogeneity [30].

We conducted stratified analyses based on the study location (Asia, the United States, Europe, or other countries), study design (cohort or cross-sectional), sample size $(\geq 10,000$ or $<10,000)$, sample population ( $<18$ years or $\geq 18$ years), ascertainment of depression (self-reported or diagnosed), ascertainment of rhinitis (self-reported or diagnosed), study quality (NOS score $>5$ or NOS score $\leq 5$ ), adjustment for confounding factors ( $\geq 8$ factors or $\leq 7$ factors), adjustment for age (yes or no), adjustment for sex (yes or no), adjustment for asthma (yes or no), adjustment for atopic dermatitis (yes or no), adjustment for household income (yes or no), and adjustment for comorbidities (yes or no).

We used funnel plots [31], Egger's tests and Begg's tests in the meta-analysis to assess publication bias. We used Stata software version 12.0 (StataCorp, College Station, $\mathrm{TX)}$ to perform the statistical analyses.

\section{Results}

\section{Literature search}

We identified 3472 potential studies, including 331 studies from PubMed, 146 studies from the Cochrane Library, and 2995 studies from EMBASE (https://doi.org/ 10.17632/ccvm3cvbtm.2). After careful screening, 3458 studies were excluded for the reasons listed in Fig. 1, and 14 studies reporting the association between rhinitis and depression met the final inclusion criteria (see Fig. 1).
The characteristics of these 14 included studies (study author, publication year, study location, study design, sample size, participants, ascertainment of rhinitis, type of rhinitis, diagnosis of rhinitis, ascertainment of depression, depression diagnostic criteria, outcomes, confounding factors, and data source) are summarized in Table 1.

\section{Characteristics and quality of the included studies}

The characteristics of the fourteen included studies are shown in Table 1. Among the included studies, four studies $[1,17,32,33]$ were cohort studies, and ten studies $[5-7,13,14,34-38]$ were cross-sectional studies. The association between rhinitis and depression was the primary outcome of interest in six studies $[7,32-34,37$, 38], the association between AR and depression was the primary outcome in nine studies $[1,5-7,13,17,35,36$, 39], and the association between NAR and depression was the primary outcome in two studies [7,35].

The included studies were published between 2008 and 2019 , and the number of participants ranged from 175 to $19.1 \pm 1.1$ million, yielding a total of $19.36 \pm 1.1$ million participants across the studies.

Four studies $[7,13,17,33]$ were conducted in the United States, six studies $[1,6,14,32,34,36]$ were conducted in Asia, three studies $[5,37,38]$ were conducted in Europe, and one study [35] was conducted in Mexico. Five studies $[1,17,32,36,38]$ involved children or adolescents, one study [34] involved only pregnant women, and the other

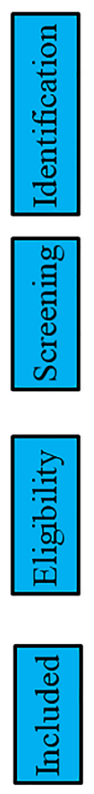

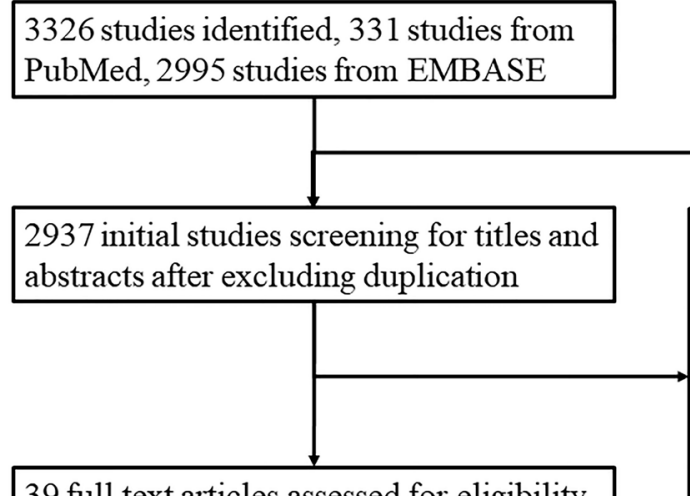

39 full text articles assessed for eligibility
1103 Excluded studies for review, metaanalysis, case report

134 Excluded studies for animal experiment

79 Excluded studies not published in English language

1582 Excluded studies for not related

2 Excluded studies for overlap data

21 Excluded studies for not related

2 Excluded studies for unusable data

14 studies included in meta-analysis

Fig. 1 Flow chart describing the study selection 


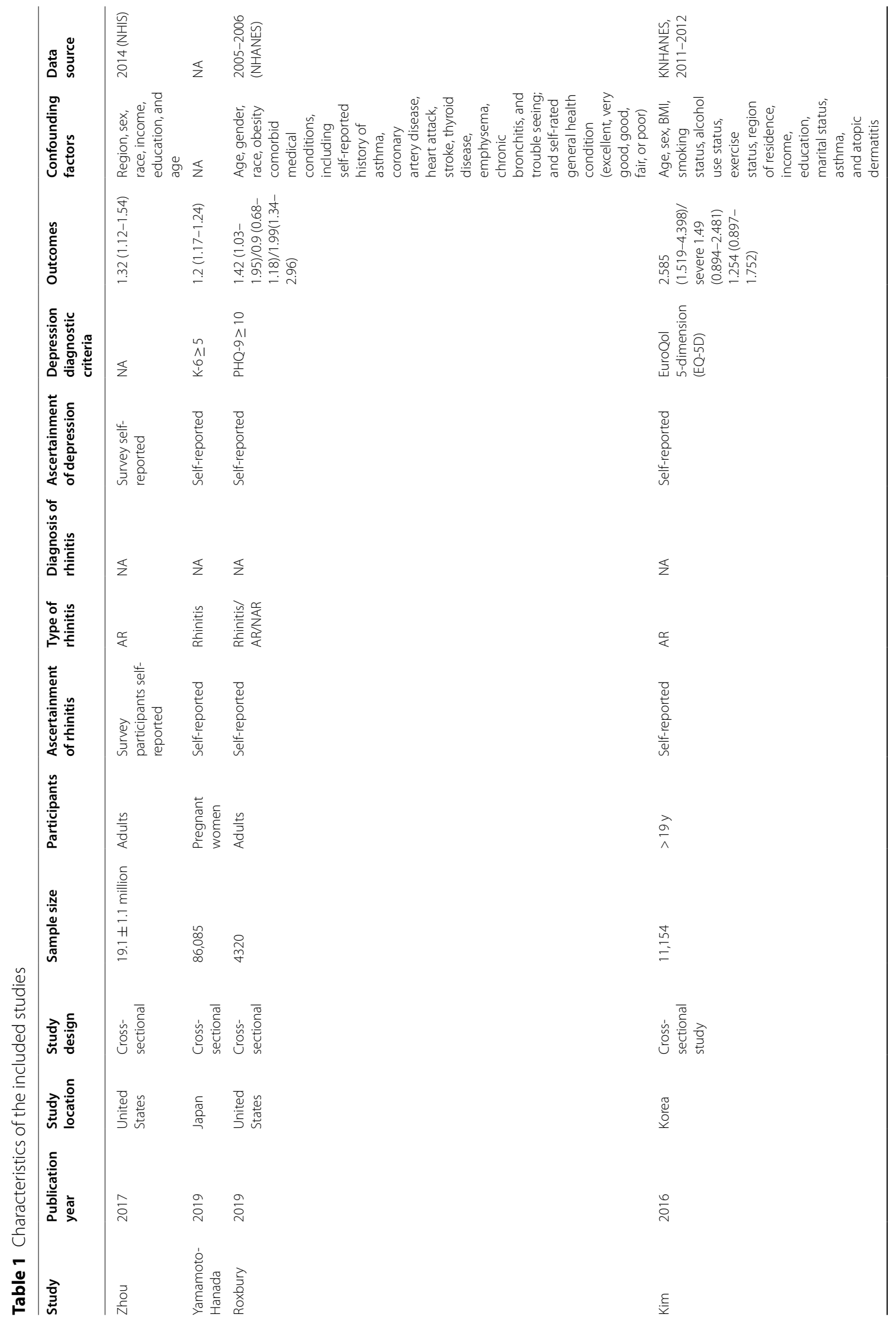




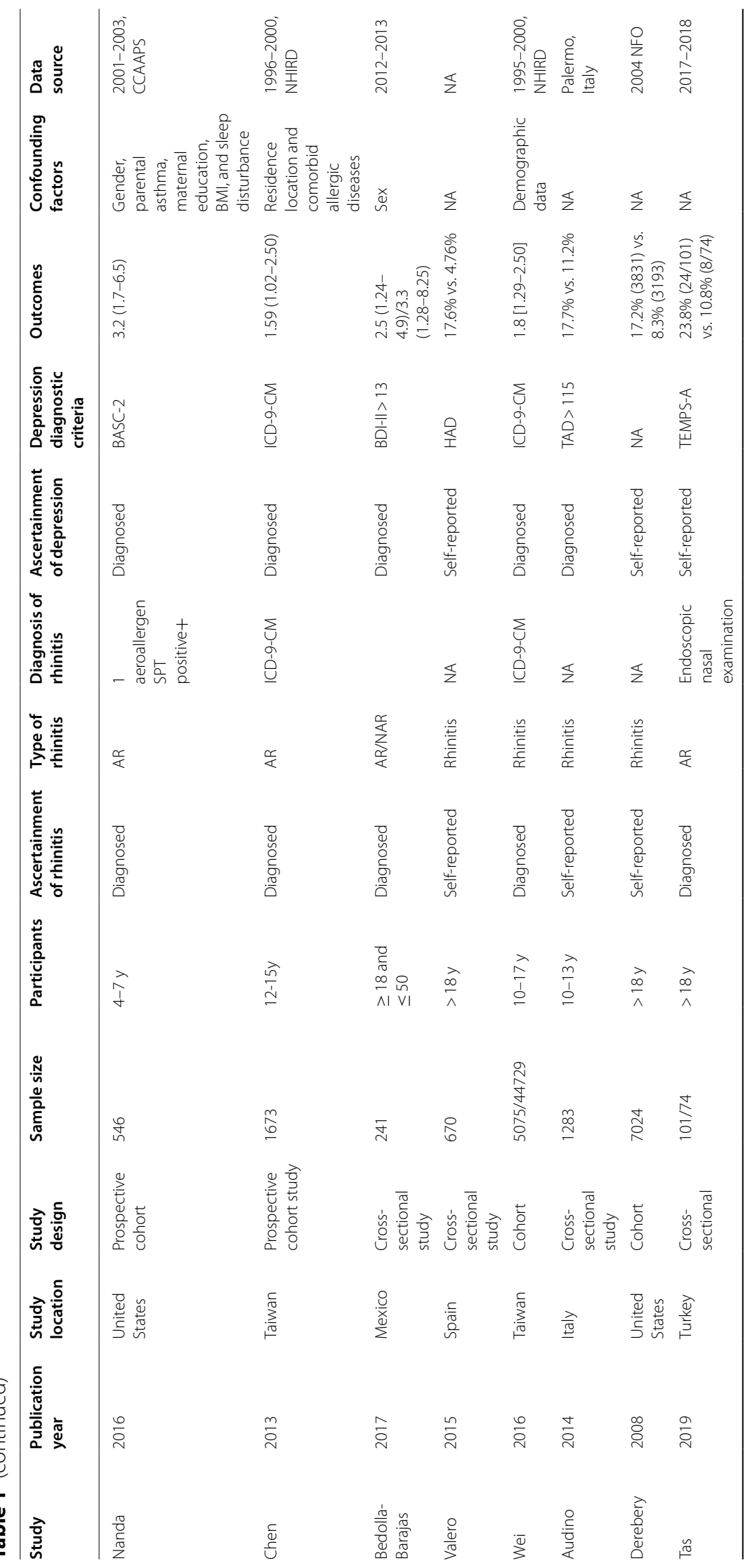




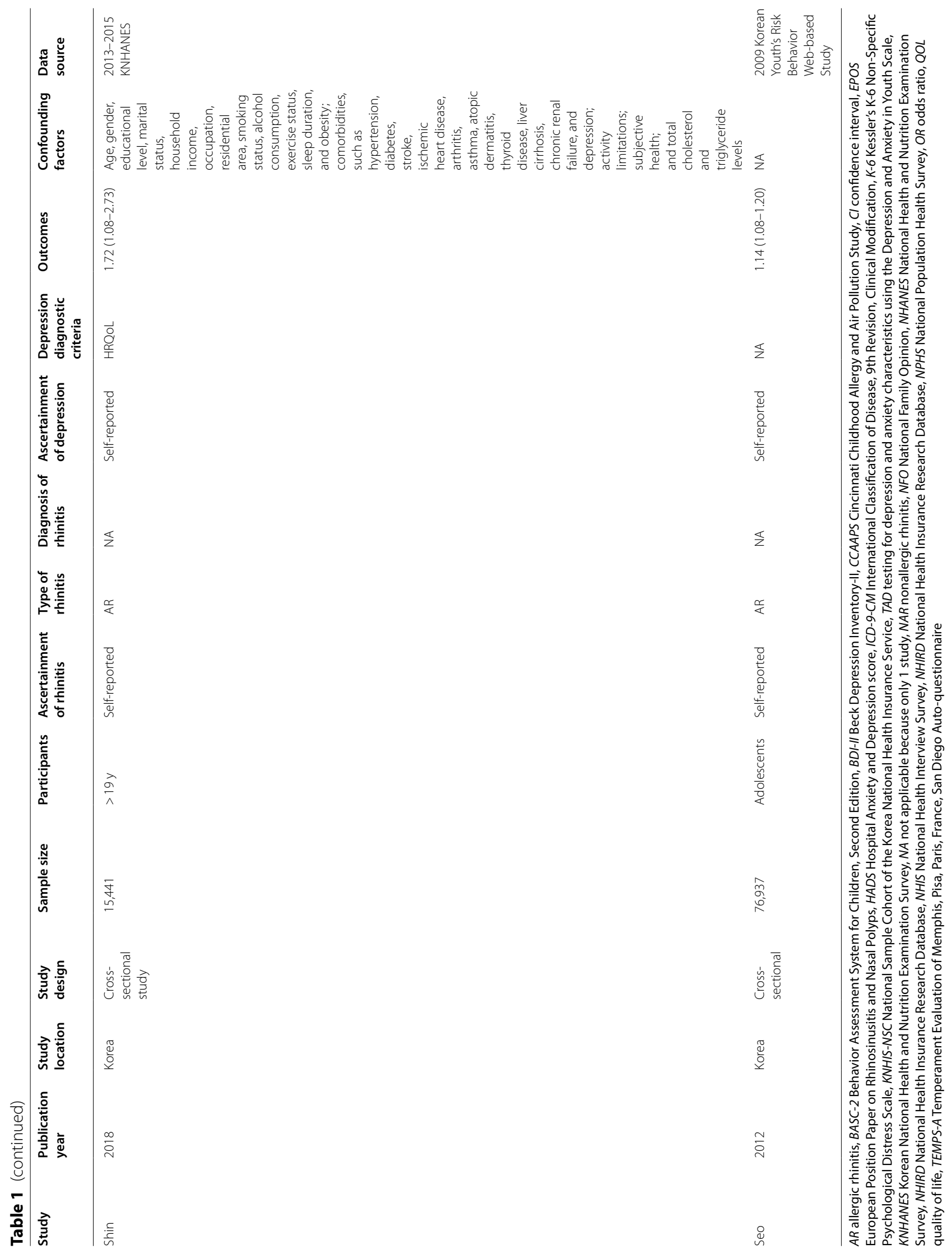


eight studies [5-7, 13, 14, 33, 35, 37] included both adult men and women.

Among the included studies, four studies [6, 7, 13, 14] adjusted for age, two studies [14,17] adjusted for asthma, and three studies adjusted for more than 8 confounding factors $[6,7,14]$.

The quality scores of the included studies ranged from 5 to 8 (https://doi.org/10.17632/ccvm3cvbtm.2), and the quality scores were considered high.

\section{Quantitative results (meta-analysis)}

Among the 14 selected studies, one study [7] found a nonsignificant association between AR and depression, while the other studies revealed an association between rhinitis, AR, or NAR and a significantly increased risk of depression. Two studies [34, 36] reported unadjusted ORs, eight studies reported adjusted ORs, and four studies $[5,33,37,38]$ reported the number of participants with and without rhinitis who developed depression.
All 14 studies reported the risks as ORs, ranging from 0.9 to 4.25 . Any type of rhinitis was associated with an increased risk of depression compared with the control with a pooled OR of 1.67 (95\% CI 1.46, 1.91). High heterogeneity was found in these studies $\left(\mathrm{I}^{2}=89.5 \%\right.$, $p<0.001$ ) (Fig. 2).

Two included studies [7, 35] (number of participants $=4561$ ) reported a significant association between NAR and depression with a pooled OR of 2.15 (95\% CI 1.49, 3.09). No significant heterogeneity was found in these studies $\left(\mathrm{I}^{2}=0, p=0.334\right)$ (Fig. 2).

\section{Stratified analyses}

\section{Allergic rhinitis and the risk of depression}

Among the fourteen studies included in our analysis, nine articles reported an association between AR and depression. Stratified analyses of several key study characteristics and clinical factors were performed to evaluate the possible sources of heterogeneity in the

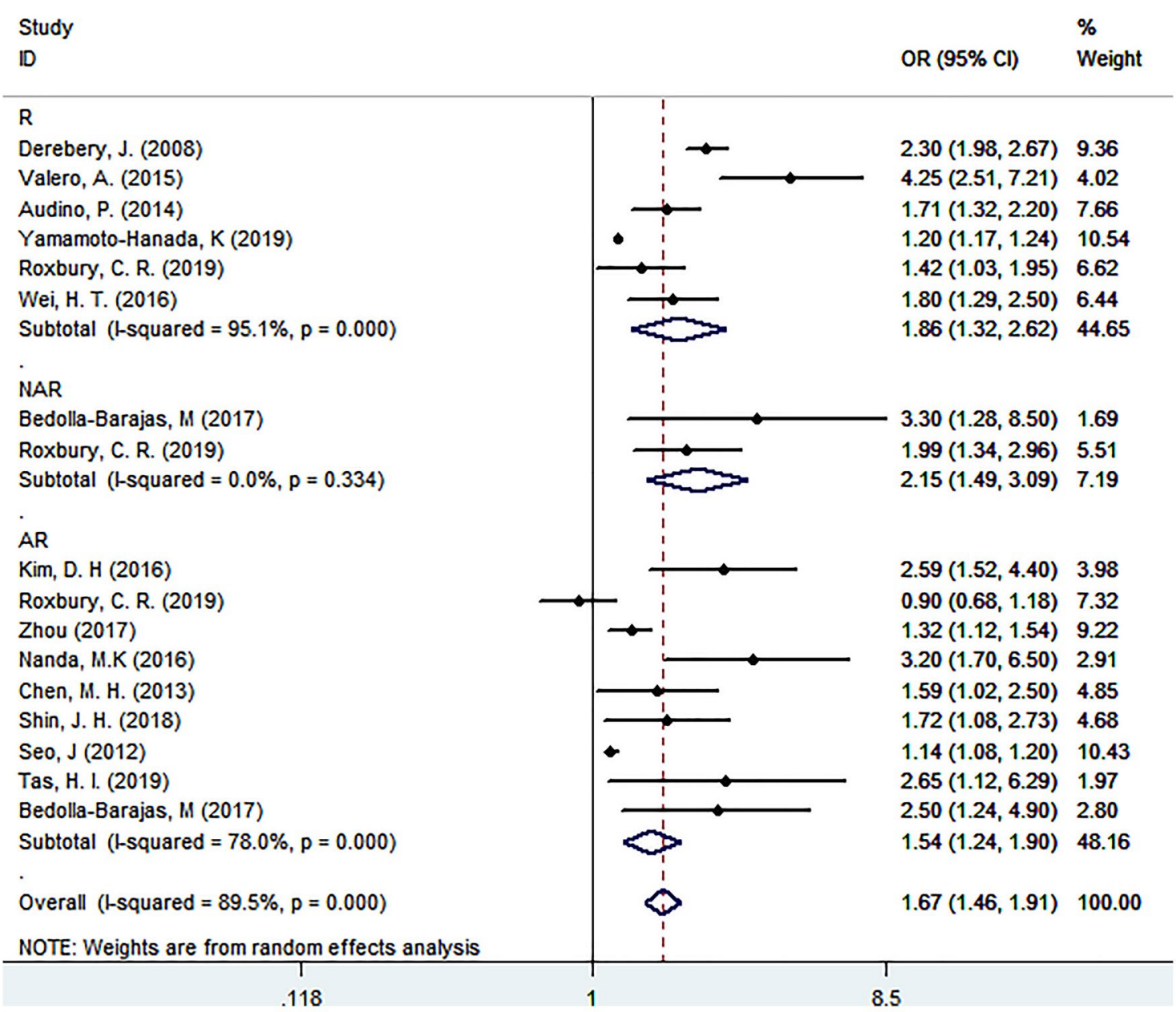

Fig. 2 Forest plot of the pooled odds ratio of the association between any type of rhinitis and depression 
Table 2 Stratified analysis of the associations between rhinitis and depression

\begin{tabular}{|c|c|c|c|c|c|c|c|c|}
\hline \multirow[t]{2}{*}{ Variables } & \multicolumn{3}{|c|}{ Allergic rhinitis and depression } & \multirow[t]{2}{*}{$p$} & \multicolumn{3}{|c|}{ Rhinitis and depression } & \multirow[t]{2}{*}{$p$} \\
\hline & Studies & OR $(95 \% \mathrm{Cl})$ & $I^{2}(p$-value $)$ & & Studies & OR $(95 \% \mathrm{Cl})$ & $P^{2}(p$-value $)$ & \\
\hline Total & 9 & $1.54(1.24,1.90)$ & $78(<0.05)$ & & 6 & $1.86(1.32,2.62)$ & $95.1(<0.05)$ & \\
\hline \multicolumn{9}{|l|}{ Study location } \\
\hline Europe & 1 & $2.65(1.12,6.28)$ & NA & $<0.05$ & 2 & $2.61(1.07,6.37)$ & $89.2(<0.05)$ & $<0.05$ \\
\hline Unites States & 3 & $1.40(0.88,2.21)$ & $85.1(<0.05)$ & & 2 & $1.85(1.15,2.96)$ & $86.1(<0.05)$ & \\
\hline Asia & 4 & $1.60(1.09,2.33)$ & $78.3(<0.05)$ & & 2 & $1.42(0.96,2.10)$ & $82.5(<0.05)$ & \\
\hline $\begin{array}{l}\text { Other } \\
\text { countries }\end{array}$ & 1 & $2.5(1.26,4.97)$ & NA & & 0 & NA & NA & \\
\hline \multicolumn{9}{|l|}{ Study design } \\
\hline Cohort & 2 & $2.15(1.09,4.25)$ & $65.4(>0.05)$ & $<0.05$ & 2 & $2.13(1.71,2.66)$ & $42.9(>0.05)$ & $>0.05$ \\
\hline Cross-sectional & 7 & $1.42(1.14,1.75)$ & $76.9(<0.05)$ & & 4 & $1.75(1.19,2.55)$ & $90(<0.05)$ & \\
\hline \multicolumn{9}{|c|}{ Sample size } \\
\hline$\geq 10,000$ & 4 & $1.41(1.12,1.78)$ & $79.1(<0.05)$ & $<0.05$ & 2 & $1.42(0.96,2.10)$ & $82.5(<0.05)$ & $<0.05$ \\
\hline$<10,000$ & 5 & $1.86(1.08,3.18)$ & $80.6(<0.05)$ & & 4 & $2.10(1.51,2.90)$ & $81.9(<0.05)$ & \\
\hline \multicolumn{9}{|c|}{ Sample population } \\
\hline Adult & 6 & $1.63(1.17,2.26)$ & $75.7(<0.05)$ & $>0.05$ & 4 & $1.93(1.21,3.10)$ & $96.7(<0.05)$ & $>0.05$ \\
\hline$<18$ years & 3 & $1.64(0.98,2.77)$ & $81.9(<0.05)$ & & 2 & $1.74(1.42,2.13)$ & $0(0.81)$ & \\
\hline \multicolumn{9}{|c|}{ Ascertainment of depression } \\
\hline Self-report & 6 & $1.34(1.09,1.65)$ & $76.4(<0.05)$ & $<0.05$ & 4 & $1.93(1.21,3.10)$ & $96.7(<0.05)$ & $>0.05$ \\
\hline Diagnosed & 3 & $2.19(1.42,3.38)$ & $38.3(>0.05)$ & & 2 & $1.74(1.42,2.13)$ & $0(0.81)$ & \\
\hline \multicolumn{9}{|c|}{ Ascertainment of rhinitis } \\
\hline Self-report & 5 & $1.29(1.05,1.57)$ & $77.4 \%(<0.05)$ & $<0.05$ & 5 & $1.88(1.27,2.77)$ & $95.9(<0.05)$ & $>0.05$ \\
\hline Diagnosed & 4 & $2.20(1.56,3.08)$ & $14.3 \%(>0.05)$ & & 1 & $1.8(1.29,2.51)$ & NA & \\
\hline \multicolumn{9}{|l|}{ Study quality } \\
\hline NOS score $>5$ & 6 & $1.6(1.17,2.18)$ & $77.3 \%(<0.05)$ & $>0.05$ & 3 & $1.39(1.09,1.78)$ & $70.4(<0.05)$ & $<0.05$ \\
\hline NOS score $\leq 5$ & 3 & $1.79(0.93,1.90)$ & $76.8 \%(<0.05)$ & & 3 & $2.37(1.66,3.39)$ & $80.1(<0.05)$ & \\
\hline \multicolumn{9}{|c|}{ Adjusted for confounding factors } \\
\hline $\begin{array}{l}\text { Minimal ( } \leq 7 \\
\text { factors) }\end{array}$ & 6 & $1.56(1.22,1.99)$ & $79.8(<0.05)$ & $>0.05$ & 5 & $1.97(1.32,2.93)$ & $96.1(<0.05)$ & $<0.05$ \\
\hline $\begin{array}{l}\text { Substantial } \\
\text { ( } \geq 8 \text { factors })\end{array}$ & 3 & $1.54(0.81,2.94)$ & $86.2(<0.05)$ & & 1 & $1.42(1.03,1.95)$ & NA & \\
\hline \multicolumn{9}{|l|}{ Adjusted for age } \\
\hline Yes & 4 & $1.43(1.0,2.03)$ & $79.6 \%(<0.05)$ & $<0.05$ & 1 & $1.42(1.03,1.95)$ & NA & $<0.05$ \\
\hline No & 5 & $1.9(1.2,3.01)$ & $79.4 \%(<0.05)$ & & 5 & $1.97(1.32,2.93)$ & $96.1(<0.05)$ & \\
\hline \multicolumn{9}{|l|}{ Adjusted for sex } \\
\hline Yes & 6 & $1.71(1.21,2.42)$ & $79.7 \%(<0.05)$ & $>0.05$ & 1 & $1.42(1.03,1.95)$ & NA & $<0.05$ \\
\hline No & 3 & $1.44(0.97,2.15)$ & $65 \%(>0.05)$ & & 5 & $1.97(1.32,2.93)$ & $96.1(<0.05)$ & \\
\hline \multicolumn{9}{|c|}{ Adjusted for asthma } \\
\hline Yes & 4 & $1.78(0.97,3.24)$ & $85.7 \%(<0.05)$ & $>0.05$ & 1 & $1.42(1.03,1.95)$ & NA & $<0.05$ \\
\hline No & 5 & $1.41(1.14,1.75)$ & $71.3 \%(<0.05)$ & & 5 & $1.97(1.32,2.93)$ & $96.1(<0.05)$ & \\
\hline \multicolumn{9}{|c|}{ Adjusted for atopic dermatitis } \\
\hline Yes & 3 & $1.86(1.41,2.46)$ & $2.6 \%(>0.05)$ & $<0.05$ & 0 & NA & NA & NA \\
\hline No & 6 & $1.38(1.09,1.74)$ & $78.6 \%(<0.05)$ & & 6 & $1.86(1.32,2.62)$ & $95.1(<0.05)$ & \\
\hline \multicolumn{9}{|c|}{ Adjusted for household income } \\
\hline Yes & 3 & $1.69(1.15,2.49$ & $68.5 \%(<0.05)$ & $>0.05$ & 0 & NA & NA & NA \\
\hline No & 6 & $1.55(1.12,2.13)$ & $78 \%(<0.05)$ & & 6 & $1.86(1.32,2.62)$ & $95.1(<0.05)$ & \\
\hline \multicolumn{9}{|c|}{ Adjusted for comorbidities } \\
\hline Yes & 3 & $1.31(0.83,2.05)$ & $78 \%(<0.05)$ & $>0.05$ & 1 & $1.42(1.03,1.95)$ & NA & $<0.05$ \\
\hline No & 6 & $1.73(1.31,2.3)$ & $82.4 \%(<0.05)$ & & 5 & $1.97(1.32,2.93)$ & $96.1(<0.05)$ & \\
\hline
\end{tabular}


included studies (Table 2). The association between AR and depression was significant (OR: 1.54, 95\% CI 1.24-1.90), and this association was consistent in all stratified analyses (Table 2). Stronger associations between AR and depression were found in the cohort studies (OR: 2.15, 95\% CI 1.09-4.25) compared with the cross-sectional studies (OR: 1.42, 95\% CI 1.14$1.75)$, in the studies with small sample sizes $(<10,000)$ (OR: $1.86,95 \%$ CI 1.08-3.18) compared to the studies with large sample sizes $(\geq 10,000)$ (OR: $1.41,95 \%$ CI $1.12-1.78)$, and in the studies conducted in Europe and other countries compared with the studies conducted in the United States and Asia (Table 2).

The diagnosis modality included in the primary studies also seemed to be related to the results. For example, studies ascertaining $\mathrm{AR}$ and depression by diagnosis demonstrated a stronger association between AR and depression incidence (OR: 2.20, 95\% CI 1.56-3.08 and OR: 2.19, 95\% CI 1.42-3.38, respectively) than the studies using self-reporting (OR: 1.29 , 95\% CI $1.05-1.57$ and OR: 1.34 , 95\% CI $1.09-$ 1.65 , respectively).

The association between $\mathrm{AR}$ and depression was strong when the studies were not adjusted for age or adjusted for the presence of atopic dermatitis (Table 2).

\section{Rhinitis and the risk of depression}

Among the fourteen studies included in our analysis, six articles reported an association between rhinitis and depression. Stratified analyses across several key study characteristics and clinical factors were performed to evaluate the possible sources of heterogeneity in the included studies (Table 2). The association between rhinitis and depression was significant (OR: 1.86, 95\% CI 1.32-2.62), and this association was consistent in all stratified analyses (Table 2). The study location, study quality, and sample size seemed to be related to the results. For example, stronger associations between rhinitis and depression were found in studies conducted in Europe (OR: 2.61, 95\% CI 1.07-6.37) compared to studies conducted in the United States (OR: 1.85, 95\% CI 1.15-2.96) or Asia (OR: 1.42, 95\% CI 0.96-2.10), in studies with a small sample size $(<10,000)$ (OR: 2.10 , 95\% CI 1.51-2.90) compared to studies with a large sample size $(\geq 10,000)$ (OR: $1.42,95 \%$ CI $0.96-2.10)$, and in studies with a NOS score $\leq 5$ (OR: $2.37,95 \%$ CI 1.66-3.39) compared to those with a NOS score $>5$ (OR: 1.39, 95\% CI 1.09-1.78) (Table 2).

The association between rhinitis and depression was stronger in the studies unadjusted for age, asthma, and comorbidities or adjusted for fewer confounding factors $(<8)$ (Table 2).

\section{Publication bias}

Potential publication bias was revealed by asymmetry funnel plots (Fig. 3). However, Begg's test was not statistically significant $(\mathrm{z}=0.95, p=0.344)$ (https://doi. org/10.17632/ccvm3cvbtm.2).

\section{Discussion}

To the best of our knowledge, this study presents the first meta-analysis to evaluate the association between rhinitis, including AR and NAR, and the incidence of depression. The results of this meta-analysis, which included 14 studies, revealed that any type of rhinitis was associated with a $67 \%$ increased risk of depression. Furthermore, our analysis revealed that AR was associated with a $54 \%$ increased risk of depression and that NAR was associated with a $115 \%$ increased risk of depression. The association persisted and remained statistically significant in all stratified analyses.

The results of this meta-analysis reveal that the patients with NAR were more likely to experience depression than the patients with AR. There are several reasons for this result. First, only two studies [7,35] with relatively small numbers of participants evaluated the association between NAR and depression; therefore, the association may be overestimated. The sample size may affect the results of the meta-analysis in the stratified analyses (Table 2). Second, depression occurs at an increased frequency in individuals with diseases with prolonged progression, such as chronic respiratory diseases, asthma, chronic atopic dermatitis, cardiovascular diseases and other systemic comorbidities $[40,41]$. The patients with NAR had an increased likelihood of a generally poor health status, and these confounding factors were not adjusted in the study by Bedolla-Barajas et al. [35]. Third, the patients with NAR had an increased likelihood of developing nasal obstruction and rhinorrhoea, and these specific presenting symptoms may lead to depression in NAR patients [7]. Fourth, the chronicity of NAR may increase the rate of depression. For example, patients with AR may present with seasonal symptoms, while patients with NAR constantly experience symptoms [7]. Collectively, future prospective cohort studies with large sample sizes are needed to clarify the results by considering additional confounding factors.

The association among AR, rhinitis and depression was significant (Table 2). Patients with AR are prone to allergic disorders with a predominance for the differentiation of CD4-positive $\mathrm{T}$ helper 2 (Th2) cells. AR with neuroinflammatory markers may trigger allergies caused by IL-4, IL- 5 and IL- 6 and, thus, affect psychopathology $[5,42,43]$, such as depression, that may be associated with increased inflammatory markers [44]. 


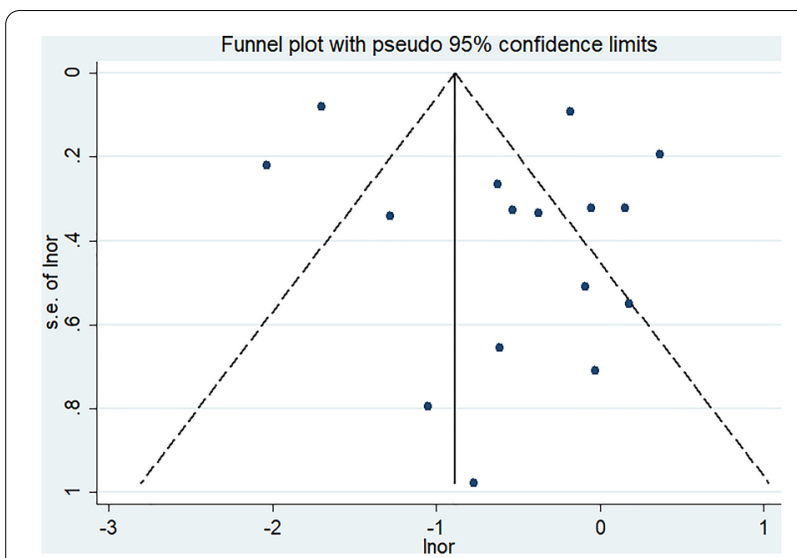

Fig. 3 Funnel plot of publication bias in the association between any type of rhinitis and depression

The association between AR and depression was stronger in the participants in Europe [5] and other countries [35] than in those in Asia $[1,6,14,36]$ and the United States $[7,13,17]$ in the stratified analysis (Table 2). Genetic and environmental factors may affect mood [5]. The study location may have affected the results via other confounding factors, such as genes, subjective health status, residential area, and occurrence of allergic disease. The association among AR, rhinitis and depression was slightly stronger in the studies with small sample sizes $(<10,000)$ than in those with large sample sizes $(\geq 10,000)$. Thus, studies with small numbers of participants may have overestimated the association among AR, rhinitis and depression.

The different methods of ascertaining depression and AR seemed to be related to the results. The studies in which depression and AR were diagnosed by physicians reported a slightly stronger association than those in which depression and AR were self-reported, and the studies with self-reporting may have been subject to recall bias [5].

Furthermore, many confounding factors are related to the results. Patients with AR often also suffer from asthma and atopic dermatitis [5, 19]. Age, asthma, atopic dermatitis, and sex were found to be related to an increased risk of depression in the stratified analysis. The studies considering fewer than 8 confounding factors may have overestimated the association between AR and depression. Future studies are needed to clarify these associations by considering additional confounding factors.

Our meta-analysis has the following limitations. First, the studies included a wide range of participants, including children and adults, in different age groups, which could result in biases. Second, some included studies reported the association between any type of rhinitis and depression without adjusting for confounding factors, such as the crude ORs or number of participants, which may have led to an overestimation of the results of the meta-analysis. Third, the treatment options for rhinitis, AR and NAR may impact their risk of expressing depressive symptoms, but the original included studies did not discuss this issue. Fourth, potential publication bias exists because we included only studies published in English. Fifth, studies reporting outcomes in alternative manners were not included in our meta-analysis, which may contribute to publication bias. For example, studies that did not evaluate the association between rhinitis and depression by ORs or conversion of ORs were excluded. Sixth, there was no analysis of the association between different types of rhinitis and different degrees of depression based on the original studies. Furthermore, bias inherent to observational studies was not eliminated in the quantitative synthesis.

The merits of this meta-analysis are as follows. First, this study evaluated the association between rhinitis and depression in a large global sample. Considering the consistent finding of an increased depression incidence associated with rhinitis, we recommend that further prospective cohort studies considering additional adjusted confounding factors should be performed to test this hypothesis. Second, this study demonstrated that the study location, study design, sample size, ascertainment of depression and rhinitis, and adjustment for confounding factors were all sources of heterogeneity.

\section{Conclusions}

In conclusion, our pooled analyses provide evidence that participants with rhinitis, including AR and NAR, had an increased risk of depression. Future studies may focus on treatment options for rhinitis and explore how AR and NAR impact the risk of expressing depressive symptoms.

\section{Abbreviations}

AR: Allergic rhinitis; BASC-2: Behavior Assessment System for Children, Second Edition; BDI-II: Beck Depression Inventory-II; CCAAPS: Cincinnati Childhood Allergy and Air Pollution Study; Cl: Confidence interval; EPOS: European Position Paper on Rhinosinusitis and Nasal Polyps; HADS: Hospital Anxiety and Depression score; ICD-9-CM: International Classification of Disease, 9th Revision, Clinical Modification; K-6: Kessler's K-6 Non-Specific Psychological Distress Scale; KNHIS-NSC: National Sample Cohort of the Korea National Health Insurance Service; TAD: Testing for depression and anxiety characteristics using the Depression and Anxiety in Youth Scale; KNHANES: Korean National Health and Nutrition Examination Survey; NA: Not applicable because only 1 study; NAR: Nonallergic rhinitis; NFO: National Family Opinion; NHANES: National Health and Nutrition Examination Survey; NHIRD: National Health Insurance Research Database; NHIS: National Health Interview Survey; NHIRD: National Health Insurance Research Database; NPHS: National Population Health Survey; OR: Odds ratio; QOL: Quality of life; TEMPS-A: Temperament Evaluation of Memphis, Pisa, Paris, France, San Diego Auto-questionnaire. 


\section{Supplementary Information}

The online version contains supplementary material available at https://doi. org/10.1186/s13223-021-00615-5.

Additional file 1. MOOSE checklist for meta-analyses of observational studies.

Additional file 2. Newcastle-Ottawa Quality Assessment Scale results for cohort and cross-sectional studies.

Additional file 3. Cumulative evidence for association of rhinitis and depression.

\section{Acknowledgements}

We thank AJE (American Journal Experts, www.aje.com) for editing the English language of our manuscript with certification number PNL583TY.

\section{Authors' contributions}

Conceptualization: JW and DX; methodology: JW, DX, HC and JH; software: JW, DX, HC and JH; validation: JW, DX, HC and JH; formal analysis: JW, DX, HC and $\mathrm{JH}$; investigation: JW, DX, HC and JH; resources: JW, DX, $\mathrm{HC}$ and $\mathrm{JH}$; data curation: JW, DX, HC and JH; writing —original draft preparation: JW and DX; writing - review and editing: $\mathrm{HC}$ and $\mathrm{JH}$; visualization: $\mathrm{HC}$ and $\mathrm{JH}$; supervision: $\mathrm{HC}$ and $\mathrm{JH}$. All authors read and approved the final manuscript.

\section{Funding}

The present study was supported by the National Science Foundation of China (Grant No. 82001593, 82102110).

\section{Availability of data and materials}

No additional data are available.

\section{Declarations}

Ethics approval and consent to participate

Not applicable; meta-analysis.

\section{Consent for publication}

Not applicable; meta-analysis.

\section{Competing interests}

The authors declare that they have no competing financial interests.

\section{Author details}

${ }^{1}$ Department of Radiology, The First Hospital of Jilin University, Changchun 130021, Jilin, China. ${ }^{2}$ Department of Emergency, Key Laboratory of Birth Defects and Related Diseases of Women and Children (Sichuan University), West China Second University Hospital, Sichuan University, Ministry of Education, Chengdu 610041, China. ${ }^{3}$ Department of Paediatrics, The First People's Hospital of Zigong, Zigong 643000, China.

Received: 10 March 2021 Accepted: 12 October 2021

Published online: 24 October 2021

\section{References}

1. Chen M-H, Su T-P, Chen Y-S, et al. Allergic rhinitis in adolescence increases the risk of depression in later life: a nationwide population-based prospective cohort study. J Affect Disord. 2013:145(1):49-53.

2. Katelaris $\mathrm{CH}$, Lee BW, Potter PC, et al. Prevalence and diversity of allergic rhinitis in regions of the world beyond Europe and North America. Clin Exp Allergy. 2012;42(2):186-207.

3. Kim J-Y, Ko I, Kim MS, Yu MS, Cho B-J, Kim D-K. Association of chronic rhinosinusitis with depression and anxiety in a nationwide insurance population. JAMA Otolaryngol Head Neck Surg. 2019;145(4):313-9.

4. Cingi C, Gevaert P, Moesges R, et al. Multi-morbidities of allergic rhinitis in adults: European academy of allergy and clinical immunology task force report. Clin Transl Allergy. 2017;7:1-12.
5. Tas HI, Caglar O. The role of anxious temperament in patients with allergic rhinitis. Saudi Med J. 2019;40(1):45-51.

6. Shin J-H, Roh D, Lee D-H, et al. Allergic rhinitis and rhinosinusitis synergistically compromise the mental health and health-related quality of life of Korean adults: a nationwide population-based survey. PLoS ONE. 2018;13(1):e0191115.

7. Roxbury CR, Qiu M, Shargorodsky J, Woodard TD, Sindwani R, Lin SY. Association between rhinitis and depression in United States adults. J Allergy Clin Immunol Pract. 2019;7(6):2013-20.

8. Settipane RA, Schwindt C. Allergic rhinitis. Am J Rhinol Allergy. 2013:27:S52-5.

9. Settipane RA, Kaliner MA. Nonallergic rhinitis. Am J Rhinol Allergy 2013;27:S48-51.

10. Fan S-J, Heinrich J, Bloom MS, et al. Ambient air pollution and depression: a systematic review with meta-analysis up to 2019 . Sci Total Environ. 2020;701:134721

11. Pilevarzadeh $M$, Amirshahi $M, A f s a r g h a r e h b a g h ~ R$, Rafiemanesh $H$, Hashemi S-M, Balouchi A. Global prevalence of depression among breast cancer patients: a systematic review and meta-analysis. Breast Cancer Res Treat. 2019:176(3):519-33.

12. Shah D, Rai P, Dwibedi N, Sambamoorthi U. Treatment for depression and health-related quality of life among adults with arthritis. Psychiatr Q. 2018;89(1):129-40

13. Zhou S, Hur K, Shen J, Wrobel B. Impact of sinonasal disease on depression, sleep duration, and productivity among adults in the United States. Laryngoscope Investig Otolaryngol. 2017;2(5):288-94.

14. Kim DH, Han K, Kim SW. Relationship between allergic rhinitis and menta health in the general korean adult population. Allergy Asthma Immunol Res. 2016:8(1):49-54

15. Schlosser RJ, Storck K, Cortese BM, Uhde TW, Rudmik L, Soler ZM. Depression in chronic rhinosinusitis: a controlled cohort study. Am J Rhinol Allergy. 2016;30(2):128-33.

16. Hsu C-L, Wang T-C, Shen T-C, Huang Y-J, Lin C-L, Sung F-C. Risk of depression in patients with chronic rhinosinusitis: a nationwide population-based retrospective cohort study. J Affect Disord. 2016:206:294-9.

17. Nanda MK, LeMasters GK, Levin L, et al. Allergic diseases and internalizing behaviors in early childhood. Pediatrics. 2016;137(1):e20151922.

18. Macdonald Kl, McNally JD, Massoud E. The health and resource utilization of Canadians with chronic rhinosinusitis. Laryngoscope. 2009;119(1):184-9.

19. Lu Z, Chen L, Xu S, et al. Allergic disorders and risk of depression: systematic review and meta-analysis of 51 large-scale studies. Ann Allergy Asthma Immunol. 2018;120(3):310.

20. Sansone RA, Sansone LA. Allergic rhinitis: relationships with anxiety and mood syndromes. Innov Clin Neurosci. 2011;8(7):12-7.

21. Eifan AO, Durham SR. Pathogenesis of rhinitis. Clin Exp Allergy. 2016:46(9):1139-51.

22. Baraniuk JN. Pathogenesis of allergic rhinitis. J Allergy Clin Immunol. 1997;99(2):S763-72

23. Novak N, Bieber T. Allergic and nonallergic forms of atopic diseases. J Allergy Clin Immunol. 2003;112(2):252-62.

24. Uher R, Payne JL, Pavlova B, Perlis RH. Major depressive disorder in DSM-5: implications for clinical practice and research of changes from DSM-IV. Depress Anxiety. 2014;31(6):459-71.

25. Zhu T, Tang J, Zhao F, Qu Y, Mu D. Association between maternal obesity and offspring Apgar score or cord pH: a systematic review and metaanalysis. Sci Rep. 2015;5:18386

26. Gou X, Yang L, Pan L, Xiao D. Association between bronchopulmonary dysplasia and cerebral palsy in children: a meta-analysis. BMJ Open. 2018;8(9):e020735.

27. Hartzel J, Agresti A, Caffo B. Multinomial logit random effects models. Stat Model. 2001;1(2):81-102.

28. Higgins JP, Thompson SG, Deeks JJ, Altman DG. Measuring inconsistency in meta-analyses. BMJ. 2003;327(7414):557-60.

29. Xiao D, Qu Y, Huang L, Wang Y, Li X, Mu D. Association between maternal overweight or obesity and cerebral palsy in children: a meta-analysis. PLoS ONE. 2018;13(10):e0205733.

30. Wu YW, Colford JM Jr. Chorioamnionitis as a risk factor for cerebral palsy: a meta-analysis. JAMA. 2000;284(11):1417-24. 
31. de Haan K, Groeneveld ABJ, de Geus HRH, Egal M, Struijs A. Vitamin D deficiency as a risk factor for infection, sepsis and mortality in the critically ill: systematic review and meta-analysis. Crit Care. 2014;18(6):1-8.

32. Wei HT, Lan W-H, Hsu J-W, et al. Risk of developing major depression and bipolar disorder among adolescents with atopic diseases: a nationwide longitudinal study in Taiwan. J Affect Disord. 2016;203:221-6.

33. Derebery J, Meltzer E, Nathan RA, et al. Rhinitis symptoms and comorbidities in the United States: burden of rhinitis in America survey. Otolaryngol Head Neck Surg. 2008;139(2):198-205.

34. Yamamoto-Hanada K, Saito M, Matsumoto K, Saito H, Ohya Y. Allergy, depression and quality of life among pregnant women in the Japan environment and childrens study (JECS). J Allergy Clin Immunol. 2019:143(2):AB279.

35. Bedolla-Barajas M, Morales-Romero J, Pulido-Guillen NA, RoblesFigueroa M, Plascencia-Dominguez BR. Rhinitis as an associated factor for anxiety and depression amongst adults. Braz J Otorhinolaryngol. 2017;83(4):432-8.

36. Seo J, Lee C, Lee D, Kim S. Suicide idea and depressive symptom in Korean adolescent with allergic disease. Neuropsychiatr Enfance Adolesc. 2012;60(5):S173.

37. Valero A, Garani V, Perea E, Garcia J, Giralt E. Anxiety and depression are directly related with allergy symptoms in patients with rhinitis, with differences depending on the type of allergy-results of animo study. Allergy Eur J Allergy Clin Immunol. 2015;70:118.

38. Audino P, La Grutta S, Cibella F, et al. Rhinitis as a risk factor for depressive mood in pre-adolescents: a new approach to this relationship. Pediatr Allergy Immunol. 2014;25(4):360-5.
39. Kim CJ, Romero R, Chaemsaithong P, Chaiyasit N, Yoon BH, Kim YM. Acute chorioamnionitis and funisitis: definition, pathologic features, and clinical significance. Am J Obstet Gynecol. 2015;213(4 Suppl):S29-52.

40. Ryu YJ, Chun E-M, Lee JH, Chang JH. Prevalence of depression and anxiety in outpatients with chronic airway lung disease. Korean J Intern Med. 2010;25(1):51-7.

41. Bahreinian S, Ball GDC, Colman I, Becker AB, Kozyrskyj AL. Depression is more common in girls with nonatopic asthma. Chest. 2011;140(5):1138-45.

42. Abbas AK, Murphy KM, Sher A. Functional diversity of helper T lymphocytes. Nature. 1996;383(6603):787-93.

43. Dowlati Y, Herrmann N, Swardfager W, et al. A meta-analysis of cytokines in major depression. Biol Psychiat. 2010;67(5):446-57.

44. Brown ES, Sayed N, Van Enkevort E, et al. A randomized, doubleblind, placebo-controlled trial of escitalopram in patients with asthma and major depressive disorder. J Allergy Clin Immunol Pract. 2018;6(5):1604-12.

\section{Publisher's Note}

Springer Nature remains neutral with regard to jurisdictional claims in published maps and institutional affiliations.
Ready to submit your research? Choose BMC and benefit from:

- fast, convenient online submission

- thorough peer review by experienced researchers in your field

- rapid publication on acceptance

- support for research data, including large and complex data types

- gold Open Access which fosters wider collaboration and increased citations

- maximum visibility for your research: over $100 \mathrm{M}$ website views per year

At BMC, research is always in progress.

Learn more biomedcentral.com/submissions 